\title{
Decision Support Model for Introduction of Gamification Solution Using AHP
}

\author{
Sangkyun Kim \\ Kangwon National University, Chuncheonsi, Gangwondo 200-701, Republic of Korea \\ Correspondence should be addressed to Sangkyun Kim; drsaviour@naver.com
}

Received 27 February 2014; Accepted 13 April 2014; Published 23 April 2014

Academic Editors: A. Amirteimoori and B. Parker

Copyright (c) 2014 Sangkyun Kim. This is an open access article distributed under the Creative Commons Attribution License, which permits unrestricted use, distribution, and reproduction in any medium, provided the original work is properly cited.

\begin{abstract}
Gamification means the use of various elements of game design in nongame contexts including workplace collaboration, marketing, education, military, and medical services. Gamification is effective for both improving workplace productivity and motivating employees. However, introduction of gamification is not easy because the planning and implementation processes of gamification are very complicated and it needs interdisciplinary knowledge such as information systems, organization behavior, and human psychology. Providing a systematic decision making method for gamification process is the purpose of this paper. This paper suggests the decision criteria for selection of gamification platform to support a systematic decision making process for managements. The criteria are derived from previous works on gamification, introduction of information systems, and analytic hierarchy process. The weights of decision criteria are calculated through a survey by the professionals on game, information systems, and business administration. The analytic hierarchy process is used to derive the weights. The decision criteria and weights provided in this paper could support the managements to make a systematic decision for selection of gamification platform.
\end{abstract}

\section{Introduction}

Motivation of organizational members is one of the most important things and is not an easy problem to solve in corporate and education environments [1]. The study on gamified class showed that the gaming approach is both more effective in improving students' knowledge and more motivational than the nongaming approach [2]. The work of [3] showed that gamification is effective in work collaboration. However, it is a dawn of research on gamification and hard to find the detailed methodologies or works which show how the gamified environments could be designed and developed.

To improve the organizational outputs of the gamified environments and to motivate the organizational members with the gamified environments effectively, the gamified environments should be designed and developed according to the interdisciplinary approaches including psychology, computer science, pedagogy, management science, economics, esthetics, demography, statistics, and industrial engineering because the basis of the gamified environments is a game and those studies are closely related with a game. Managements might easily face with the problem when they select and introduce the gamification platform because the gamification platform has convergent characteristics of interdisciplinary areas described above. Providing a systematic decision making method for gamification process is the purpose of this paper. This paper suggests the decision criteria and weights for the selection of gamification platform to support a systematic decision making process for managements.

The following parts of this paper are organized in three parts. Firstly, previous works are reviewed including the recent approach of gamification, methodologies for selection and introduction of information systems, and analytic hierarchy process (AHP). Secondly, the decision criteria, weights, and a case study are provided. Finally, the implication of this study and further research issues are summarized in the Conclusion section.

\section{Related Work}

Previous works on the following topics are summarized in this section. Firstly, the definition and trend of gamification research and previous works on gamification supporting 
platforms are summarized. Secondly, the methodologies for selection and introduction of information systems are reviewed because the gamification supporting platform is a kind of the information systems. Thirdly, the concept and previous works on AHP are provided.

2.1. Gamification and Supporting Platforms. Gamification is defined as the use of various elements which could be used in game design in nongame contexts including workplace collaboration, marketing, education, military, and medical services [4]. The recent works on gamification are summarized in Table 1.

The work of [5] defined the gamification platform as "It comes complete with reward features for points, levels, badges, virtual goods, Facebook credits, and coupons. There are installable widgets for notifications, progress, avatars, profiles, leaderboards, social sharing. There are published APIs for deep integration, back-end admin consoles for set up, and full reporting and metrics." There are many kinds of platforms for gamification. The list of some leading platforms includes Gamify, Badgeville, Bunchball, Big Door Media, CrowdTwist, Cynergy, SpectrumDNA, Reputely, iActionable, Scvngr, Manumatix, and Leapfrog Builders.

\subsection{Methodologies for Selection and Introduction of Infor-} mation Systems. METHOD/1 supports the introduction of enterprise information systems and breaks down each phase of introduction process into smaller steps named segments and tasks. A series of manuals of METHOD/1 provides these steps in detail $[6,7]$.

ASAP is SAP's rapid implementation supporting tool designed to streamline and standardize the implementation of SAP products. ASAP aims to optimize time, quality, and efficient use of resources. ASAP supports the entire team which includes internal team members from the customer company and external consultants such as project manager, business process consultants, and the technical staffs.

The work of [8] proposed integrated methodology framework which is composed of patterns, scenarios, road map, components, and repository. The components offer detailed functional tools needed in the implementation path, which includes the support system for solution introduction and evaluation.

The work of [9] provides methodology which consists of process and criteria to support selection activities of the information security systems. It presents the rating approach for prioritizing security systems and the hierarchical structure of process and criteria.

The work of [10] summarized quality attributes of software products. They found that there are different schools/opinions/traditions concerning the properties of critical systems and the best methods to develop them are performance (from the tradition of hard real-time systems and capacity planning), dependability (from the tradition of ultrareliable, fault-tolerant systems), security (from the traditions of the government, banking, and academic communities), and safety (from the tradition of hazard analysis and system safety engineering).

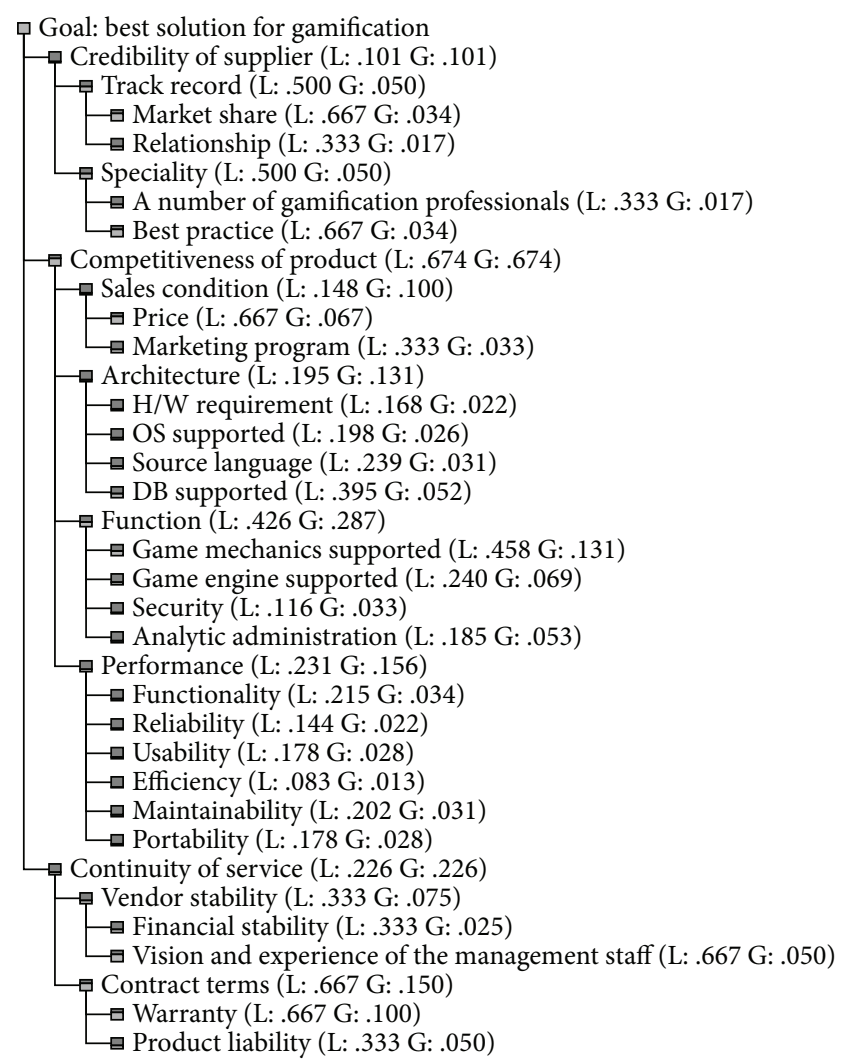

FIGURE 1: Weights of decision criteria for gamification platform.

ISO/IEC 9126 provides an international standard for the evaluation of software quality. ISO/IEC 9126 aims to solve the problems of human biases that could cause a negative impact on the selection and introduction of software. The human biases include unclear goal of the project, changing priorities after the kickoff of a project. To solve these problems, ISO/IEC 9126 suggests common goals of software selection and introduction projects which are as follows [11].

(i) Functionality: a set of attributes which provide a set of functions and their specified properties. These attributes provide suitability, accuracy, interoperability, security, and functionality compliance.

(ii) Reliability: a set of attributes which guarantee the performance level under stated conditions for a stated period of time. These attributes provide maturity, fault tolerance, recoverability, and reliability compliance.

(iii) Usability: a set of attributes which make easy to use, and the individual assessment of use by a set of users. These attributes provide understandability, learnability, operability, attractiveness, and usability compliance.

(iv) Efficiency: a set of attributes which guarantee the effective balance between inputs and outputs of the system. The inputs mean the amount of resources used for the system. The outputs mean the performance level of the system. The attributes provide time behavior, resource utilization, and efficiency compliance. 
TABLE 1: Previous works on gamification.

Previous

works

[12]

[13]

[14]

[15]

[3]

[16]

[17]

[19]
Key characteristics

It classifies the gamification approaches into the following: focusing on the technological aspects of computer games, focusing on the behavior evoked by computer games, and focusing on the design of computer games. It provides some case studies which show the process and benefits of gamification

It describes the characteristics of generation $\mathrm{Y}$ and the key elements of games that deserve a place in the enterprise including performance, achievement, and social interaction

It shows the interaction matrix of basic human desires and game mechanics including points, levels, challenges, virtual goods, leaderboards, and gifting. It provides the recent cases of gamification such as the frequent flyer programs, Foursquare, and Nike Plus

It describes the concept, benefits, key elements and mechanics of game design, and various cases of gamification

It shows the patterns of user activity in an enterprise social network service after the removal of game elements. It proved that the removal of game elements reduced overall participation within the SNS

It provides an experiment in computer science class which provides more frequent commits using a social software application. This study shows that the game elements are effective to motivate engineering students

It provides examples of social games which show behavioral economic biases related to the loss aversion tendency which is one of the key factors of behavioral economics and prospect theory

It provides the classification of engineering students based on the Bartle's game player types using the online survey which consists of 24 questionnaires

Synthesis with respect to:

goal: best solution for gamification

overall inconsistency $=0.04$

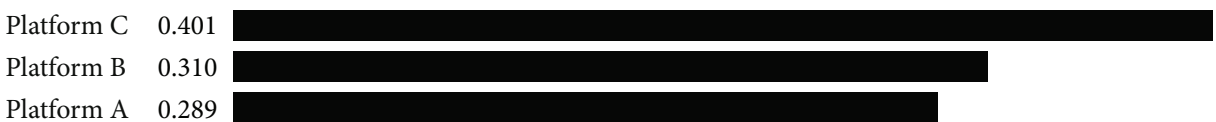

Figure 2: Synthesis result of the selection problem (exported from Expert Choice).

(v) Maintainability: a set of attributes which mean easiness for specified modifications of the system. These attributes provide analyzability, changeability, stability, testability, and maintainability compliance.

(vi) Portability: a set of attributes which support the system to be transferred from one environment to another. These attributes provide adaptability, installability, coexistence, replaceability, and portability compliance.

2.3. AHP. The AHP is a structured technique which supports a complex situation of decision making. It was proposed by Saaty in the 1970s based on mathematics and has been widely studied and used since then. It can be used in group decision making situation and has been used in various fields such as education, industry, and government.

Using the AHP, the decision problem is decomposed and structured into a hierarchy of easily understandable subproblems. One of the most important things is that each subproblem should guarantee independency. Each subproblem might be tangible or intangible aspect of the decision problem. After the building of the structured hierarchy, the decision makers judge pairwise comparison for every element of subproblems. The pairwise comparison is the process which judges the relative impact or importance of each element. In the pairwise comparison process, the
TABLE 2: Previous works on AHOP.

\begin{tabular}{ll}
\hline $\begin{array}{l}\text { Previous } \\
\text { works }\end{array}$ & Key characteristics \\
\hline$[18,20]$ & $\begin{array}{l}\text { It describes the definition, calculation procedures, } \\
\text { and application areas of AHP method }\end{array}$ \\
\hline$[21]$ & $\begin{array}{l}\text { It provides a decision making model for selection } \\
\text { of automobile using AHP }\end{array}$ \\
\hline$[22]$ & $\begin{array}{l}\text { It provides the decision criteria and decision } \\
\text { model, which are based on AHP, for introduction } \\
\text { of expert system which could be used in } \\
\text { education environments }\end{array}$ \\
\hline$[23]$ & $\begin{array}{l}\text { It shows a decision model which supports an } \\
\text { introduction of multimedia authoring tool for } \\
\text { multiple decision makers }\end{array}$ \\
\hline
\end{tabular}

decision makers can use concrete data about the elements or use their intuitive and professional judgments about the elements. Using of the human judgments is the essence of the AHP. Table 2 summarizes previous works on AHP.

\section{Decision Supporting Model Using AHP}

This section provides the decision criteria and weights for the selection of gamification platform. The decision criteria are 


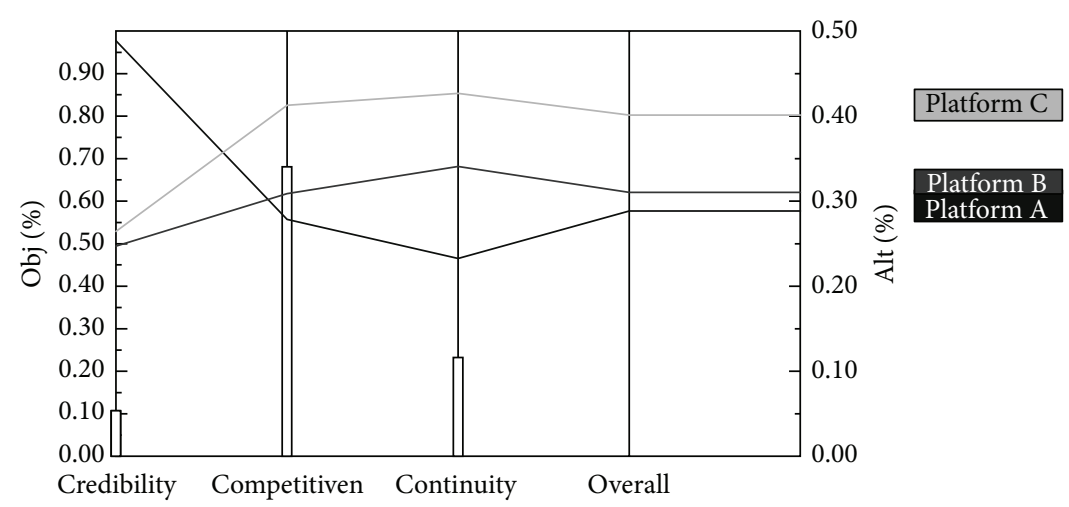

FIgURE 3: Sensitivity analysis (exported from Expert Choice).

derived from previous works on gamification and information systems.

The weights of decision criteria are calculated through a survey by the professionals using AHP. Also, a case study is provided to show a functionality and practical value of the decision criteria and weights.

3.1. Decision Criteria for Gamification Platform. This paper takes $[8,9]$ to suggest the first and second level of criteria. $[3,10-17]$ are used to derive third level of criteria. The decision criteria for the selection of gamification platform are shown in Table 3.

3.2. Weights of Decision Criteria for Gamification Platform. Judgments were elicited from the eight professionals on game, information systems, and business administration.

Expert Choice was used to rate the priorities among criteria. For example, the competitiveness of product was the most important criteria in level 2. After inputting the criteria and their importance into Expert Choice, the priorities from each set of judgments were found and recorded as shown in Figure 1.

The decision model classifies the goal, decision criteria, and variables into four major levels. The highest level of the hierarchy is the overall goal, to select the best gamification platform. Level 2, level 3, and level 4 represent the criteria in selecting the gamification platform. The overall consistency of the input judgments at all levels is within the acceptable ratio of 0.1 , as recommended by Saaty et al. [18].

\section{A Case Study}

4.1. Background. In this case study, AHP and the proposed selection model for gamification platform were applied to a particular project in which X Company located in South Korea wanted to select gamification platform. There was no relationship in corporate governance structure between gamification platform vendors and X Company, so vendors and products were treated as independent. Three gamification platforms were prepared for decision alternatives. In this
TABLE 3: Decision criteria for gamification platform.

\begin{tabular}{|c|c|c|}
\hline 1st level criteria & 2nd level criteria & 3rd level criteria \\
\hline \multirow{2}{*}{$\begin{array}{l}\text { Credibility of } \\
\text { supplier }\end{array}$} & Track record & $\begin{array}{l}\text { Market share } \\
\text { Relationship }\end{array}$ \\
\hline & Speciality & $\begin{array}{l}\text { A number of gamification } \\
\text { professionals } \\
\text { Best practice }\end{array}$ \\
\hline \multirow{4}{*}{$\begin{array}{l}\text { Competitiveness } \\
\text { of product }\end{array}$} & Sales condition & $\begin{array}{l}\text { Price } \\
\text { Marketing program }\end{array}$ \\
\hline & Architecture & $\begin{array}{l}\text { Hardware requirement } \\
\text { OS supported } \\
\text { Source language } \\
\text { DB supported }\end{array}$ \\
\hline & Function & $\begin{array}{l}\text { Game mechanics supportec } \\
\text { Game engine supported } \\
\text { Security } \\
\text { Analytic administration }\end{array}$ \\
\hline & Performance & $\begin{array}{l}\text { Functionality } \\
\text { Reliability } \\
\text { Usability } \\
\text { Efficiency } \\
\text { Maintainability } \\
\text { Portability }\end{array}$ \\
\hline \multirow{2}{*}{$\begin{array}{l}\text { Continuity of } \\
\text { service }\end{array}$} & Vendor stability & $\begin{array}{l}\text { Financial stability } \\
\text { Vision and experience of } \\
\text { the management staff }\end{array}$ \\
\hline & Contract terms & $\begin{array}{l}\text { Warranty } \\
\text { Product liability }\end{array}$ \\
\hline
\end{tabular}

paper, the alternatives are called platform A, platform B, and platform C.

4.2. Comparative Judgments on Three Gamification Platforms. Five staffs participated to compare each product using Expert Choice software. Table 4 shows the normalized priority weights of the gamification platforms.

The overall priority of the gamification platform alternatives is calculated by multiplying its global priority with the corresponding weight along the hierarchy. Synthesizing all the elements using Expert Choice, the results are shown in 
TABLE 4: Normalized priority weights of three gamification platforms.

\begin{tabular}{|c|c|c|c|c|c|}
\hline \multicolumn{3}{|c|}{ Decision criteria and weights } & \multicolumn{3}{|c|}{ Platforms' priority weights } \\
\hline Level 1 & Level 2 & Level 3 & Platform A & Platform B & Platform C \\
\hline \multirow{4}{*}{$\begin{array}{l}\text { Credibility of supplier } \\
\text { (L: } 0.101 \text { G: } 0.101 \text { ) }\end{array}$} & \multirow{2}{*}{ Track record (L: 0.500 G: 0.050) } & Market share (L: 0.667 G: 0.034) & 0.019 & 0.01 & 0.006 \\
\hline & & Relationship (L: 0.333 G: 0.017) & 0.002 & 0.003 & 0.009 \\
\hline & \multirow[t]{2}{*}{ Speciality (L: 0.500 G: 0.050) } & $\begin{array}{l}\text { A number of gamification } \\
\text { professionals (L: } 0.333 \text { G: } 0.017 \text { ) }\end{array}$ & 0.009 & 0.004 & 0.003 \\
\hline & & Best practice (L: 0.667 G: 0.034) & 0.019 & 0.007 & 0.008 \\
\hline \multirow{16}{*}{$\begin{array}{l}\text { Competitiveness of } \\
\text { product (L: } 0.674 \text { G: } 0.674 \text { ) }\end{array}$} & \multirow{2}{*}{ Sales condition (L: 0.148 G: 0.100 ) } & Price (L: 0.667 G: 0.067) & 0.011 & 0.02 & 0.037 \\
\hline & & $\begin{array}{l}\text { Marketing program } \\
\text { (L: } 0.333 \text { G: } 0.033 \text { ) }\end{array}$ & 0.003 & 0.006 & 0.019 \\
\hline & \multirow{3}{*}{ Architecture (L: 0.195 G: 0.131) } & $\begin{array}{l}\text { H/W requirement } \\
\text { (L: } 0.168 \text { G: } 0.022)\end{array}$ & 0.006 & 0.012 & 0.012 \\
\hline & & OS supported (L: 0.198 G: 0.026) & 0.014 & 0.006 & 0.005 \\
\hline & & $\begin{array}{l}\text { Source language } \\
\text { (L: } 0.239 \text { G: } 0.031)\end{array}$ & 0.004 & 0.009 & 0.017 \\
\hline & \multirow{5}{*}{ Function (L: 0.426 G: 0.287) } & DB supported (L: 0.395 G: 0.052 ) & 0.029 & 0.012 & 0.008 \\
\hline & & $\begin{array}{l}\text { Game mechanics supported } \\
\text { (L: } 0.458 \text { G: } 0.131 \text { ) }\end{array}$ & 0.016 & 0.073 & 0.042 \\
\hline & & $\begin{array}{l}\text { Game engine supported } \\
\text { (L: } 0.240 \text { G: } 0.069 \text { ) }\end{array}$ & 0.007 & 0.011 & 0.038 \\
\hline & & Security (L: 0.116 G: 0.033) & 0.002 & 0.006 & 0.019 \\
\hline & & $\begin{array}{l}\text { Analytic administration } \\
\text { (L: } 0.185 \text { G: } 0.053 \text { ) }\end{array}$ & 0.026 & 0.011 & 0.029 \\
\hline & \multirow{6}{*}{ Performance (L: 0.231 G: 0.156) } & Functionality (L: 0.215 G: 0.034) & 0.019 & 0.009 & 0.009 \\
\hline & & Reliability (L: 0.144 G: 0.022) & 0.012 & 0.004 & 0.002 \\
\hline & & Usability (L: 0.178 G: 0.028) & 0.015 & 0.008 & 0.008 \\
\hline & & Efficiency (L: 0.083 G: 0.013) & 0.002 & 0.004 & 0.007 \\
\hline & & $\begin{array}{l}\text { Maintainability } \\
\text { (L: } 0.202 \text { G: } 0.031 \text { ) }\end{array}$ & 0.003 & 0.006 & 0.017 \\
\hline & & Portability (L: 0.178 G: 0.028 ) & 0.015 & 0.006 & 0.003 \\
\hline \multirow{4}{*}{$\begin{array}{l}\text { Continuity of service } \\
\text { (L: } 0.226 \text { G: } 0.226 \text { ) }\end{array}$} & \multirow[t]{2}{*}{$\begin{array}{l}\text { Vendor stability } \\
\text { (L: } 0.333 \text { G: } 0.075 \text { ) }\end{array}$} & $\begin{array}{l}\text { Financial stability } \\
\text { (L: } 0.333 \text { G: } 0.025 \text { ) }\end{array}$ & 0.014 & 0.007 & 0.007 \\
\hline & & $\begin{array}{l}\text { Vision and experience of the } \\
\text { management staff } \\
\text { (L: } 0.667 \text { G: } 0.050)\end{array}$ & 0.024 & 0.028 & 0.011 \\
\hline & \multirow{2}{*}{$\begin{array}{l}\text { Contract terms } \\
\text { (L: } 0.667 \text { G: } 0.150)\end{array}$} & Warranty (L: 0.667 G: 0.100) & 0.008 & 0.031 & 0.056 \\
\hline & & $\begin{array}{l}\text { Product liability } \\
\text { (L: } 0.333 \text { G: } 0.050)\end{array}$ & 0.008 & 0.015 & 0.028 \\
\hline
\end{tabular}

Figure 2. It shows that gamification platform $\mathrm{C}$ scored the highest in the result, followed by platform $\mathrm{B}$ and platform $\mathrm{A}$.

4.3. Sensitivity Analysis. Sensitivity analysis attempts to check the impact of change in the input data or parameters of the proposed gamification platform. Relatively small changes in the hierarchy or judgment may lead to a different outcome. Using Expert Choice, the sensitivity of the outcome can be tested. Figure 3 shows a sensitivity analysis of the alternative priorities with respect to changes in the relative weights of the criteria.

4.4. Validation. The goal of the validation was to ensure that the results derived from this model were reasonable. That is to say, to examine if the gamification expert's knowhow could be substituted with the proposed decision criteria and weighted priorities is the goal of this validation.

Three gamification experts, apart from five staffs who participated in comparative judgments on three gamification platforms, helped to validate the proposed model. The judgments of three gamification experts with their own gamification knowhow and the result derived from this model as described in Section 4.2 were compared to assess the functionality of this model. Three gamification experts were not informed of which platform had been selected using this model. Background information on X Company and whitepapers on three gamification platforms were provided to gamification experts. After reviewing this information, three gamification experts chose the best platform and 
the worst platform for X Company. They chose platform C as the best and platform $\mathrm{A}$ as the worst. The gamification experts' choice based on their knowhow was matched with the result described in Section 4.2.

\section{Conclusion}

This paper provides the decision criteria and weights for the selection of gamification platform. The decision criteria are derived from previous works on gamification and information systems. The weights of decision criteria are calculated through a survey by the professionals using AHP. Also, a case study that X Company used the decision criteria and weights for the selection of gamification platform in is provided to show a functionality and practical value of this paper.

The implications of this paper are summarized as follows.

(i) As described at the introduction part of this paper, it is only a short time since gamification approaches began, so the decision criteria and weights provided in this paper could support the selection of gamification platform.

(ii) The decision criteria on gamification platform would support the managements to understand what they should consider for successful gamification.

Limitation and further research issues are summarized as follows.

(i) It lacks providing sufficient pool of survey respondents for pairwise comparison, so a number of survey respondents should be increased to improve the reliability of the weights of decision criteria for gamification platform.

(ii) A case study which validates the functionality of the decision criteria for gamification platform is provided. However, the validation is not suffonsified because it only provides a single case.

(iii) Decision criteria for gamification platform should be enriched and revised through the in-depth and interdisciplinary reviews on human behavior, theory of organizational structure, theory of organizational behavior, content theory, process theory, game design, information systems, and so on.

\section{Conflict of Interests}

The author declares that there is no conflict of interests regarding the publication of this paper.

\section{Acknowledgments}

This study is supported by Kangwon National University. Also, it was supported by Basic Science Research Program through the National Research Foundation of Korea (NRF) funded by the Ministry of Education (NRF-2013R1A1A2A10058460).

\section{References}

[1] J. Husman and W. Lens, "The role of the future in student motivation," Educational Psychologist, vol. 34, no. 2, pp. 113-125, 1999.

[2] M. Papastergiou, "Digital game-based learning in high school computer science education: impact on educational effectiveness and student motivation," Computers \& Education, vol. 52, no. 1, pp. 1-12, 2009.

[3] J. Thom, D. Millen, and J. DiMicco, "Removing gamification from an enterprise SNS," in Proceedings of the ACM Conference on Computer Supported Cooperative Work (CSCW '12), pp. 1067-1070, February 2012.

[4] S. Deterding, R. Khaled, L. E. Nacke, and D. Dixon, "Gamification: toward a definition," in Proceedings of the Gamification Workshop (CHI '11), 2011.

[5] J. Barber, "12 Gamification Platforms and The Start of A \$1. 6B Industry," 2011, http://johnbarberblog.com.

[6] M. D. Fraser and V. K. Vaishnavi, "A formal specifications maturity: model," Communications of the ACM, vol. 40, no. 12, pp. 95-103, 1997.

[7] M. Monheit and A. Tsafrir, "Information systems architecture: a consulting methodology," in Proceedings of the IEEE International Conference on Computer Systems and Software Engineering (COMPEURO '90), pp. 568-572, May 1990.

[8] C. S. Leem and S. Kim, "Introduction to an integrated methodology for development and implementation of enterprise information systems," Journal of Systems and Software, vol. 60, no. 3, pp. 249-261, 2002.

[9] S. Kim and H. J. Lee, "A study on decision consolidation methods using analytic models for security systems," Computers \& Security, vol. 26, no. 2, pp. 145-153, 2007.

[10] M. Barbacci, M. H. Klein, T. A. Longstaff, and C. B. Weinstock, Quality Attributes, Software Engineering Institute, Carnegie Mellon University, 1995.

[11] ISO, "ISO9126-1: software engineering-product quality-part 1: quality model," ISO/IEC 9126-1:2001, International Organization for Standardization, 2001.

[12] J. V. Bree, "The end of the rainbow: in search of crossing points between organizations and games," in Proceedings of the 5th International Conference of the Digital Research Association: Think Design Play (DIGRA '11), January 2011.

[13] Bunchball, Enterprise Gamification: The Gen Y Factor, Bunchball, 2012.

[14] Bunchball, Gamification 101: An Introduction to the Use of Game Dynamics to Influence Behavior, Bunchball, 2010.

[15] J. McGonigal, Reality Is Broken: Why Games Make Us Better and How They Can Change the World, Penguin, 2011.

[16] L. Singer and K. Schneider, "It was a bit of a race: gamification of version control," in Proceedings of the 2nd International Workshop on Games and Software Engineering, 2012.

[17] J. Hamari, "Perspectives from behavioral economics to analyzing game design patterns: loss aversion in social games," in Proceedings of the Social Games Workshop (CHI '11), May 2011.

[18] T. L. Saaty, L. Vargas, and T. Saaty, Fundamentals of Decision Making and Priority Theory with the Analytic Hierarchy Process, RWS Publications, 1994.

[19] S. Kim and F. I. S. Ko, "Toward gamified classroom: classification of engineering students based on the Bartle's player types model," International Journal of Digital Content Technology and Its Applications, vol. 7, pp. 25-31, 2013. 
[20] T. L. Saaty, The Analytic Network Process: Decision Making with Dependence and Feedback, RWS Publications, 2001.

[21] D.-H. Byun, "The AHP approach for selecting an automobile purchase model," Information \& Management, vol. 38, no. 5, pp. 289-297, 2001.

[22] C. S. Kim and Y. Yoon, "Selection of a good expert system shell for instructional purposes in business," Information \& Management, vol. 23, no. 5, pp. 249-262, 1992.

[23] V. S. Lai, R. P. Trueblood, and B. K. Wong, "Software selection: a case study of the application of the analytical hierarchical process to the selection of a multimedia authoring system," Information \& Management, vol. 36, no. 4, pp. 221-232, 1999. 


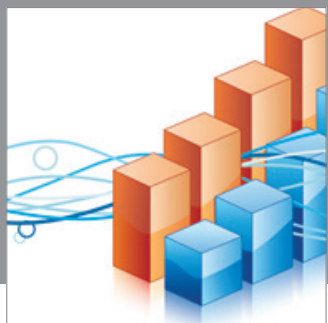

Advances in

Operations Research

mansans

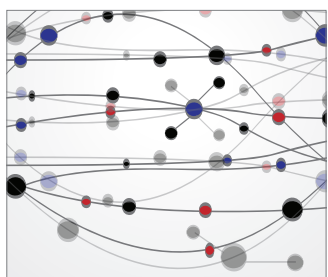

The Scientific World Journal
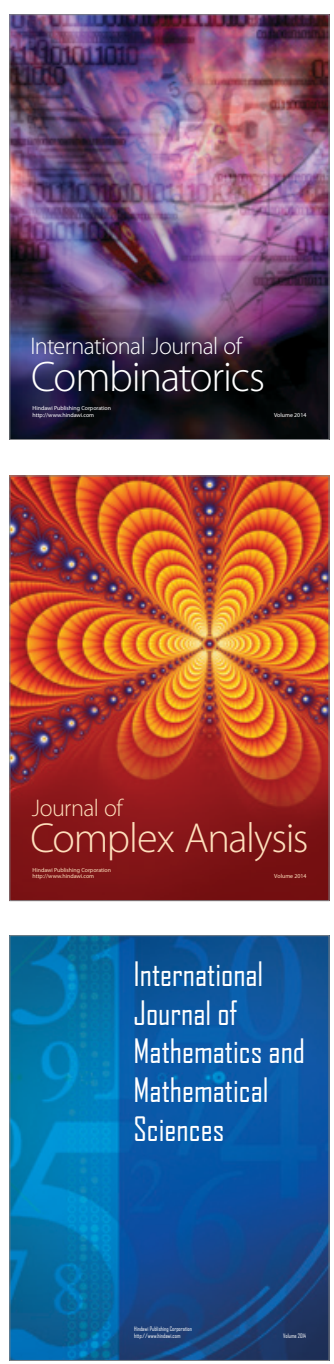
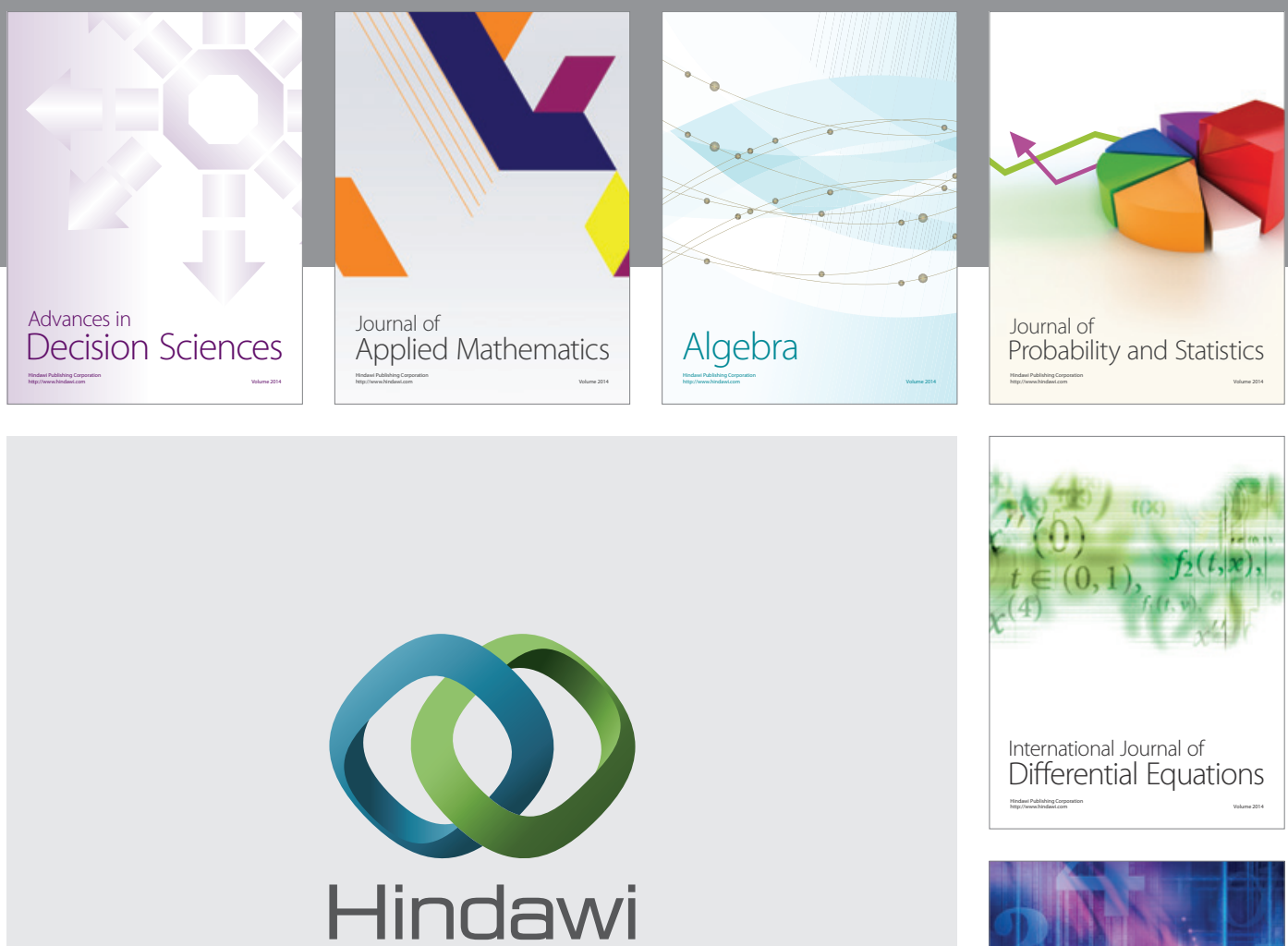

Submit your manuscripts at http://www.hindawi.com
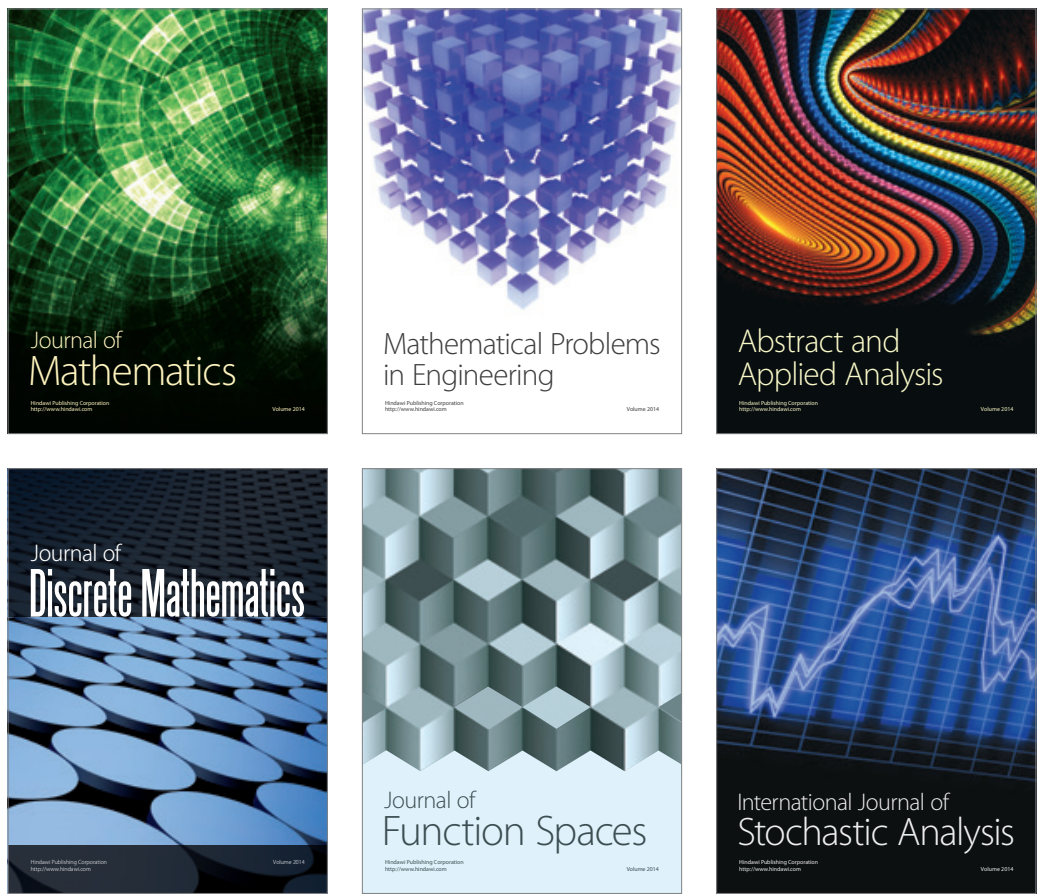

Journal of

Function Spaces

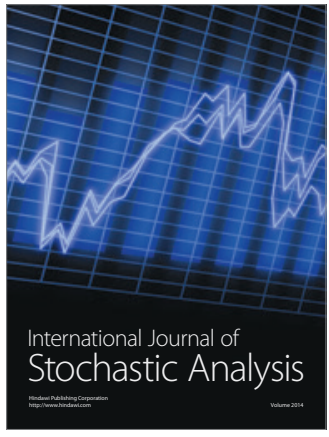

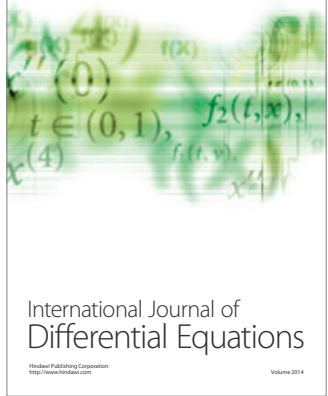
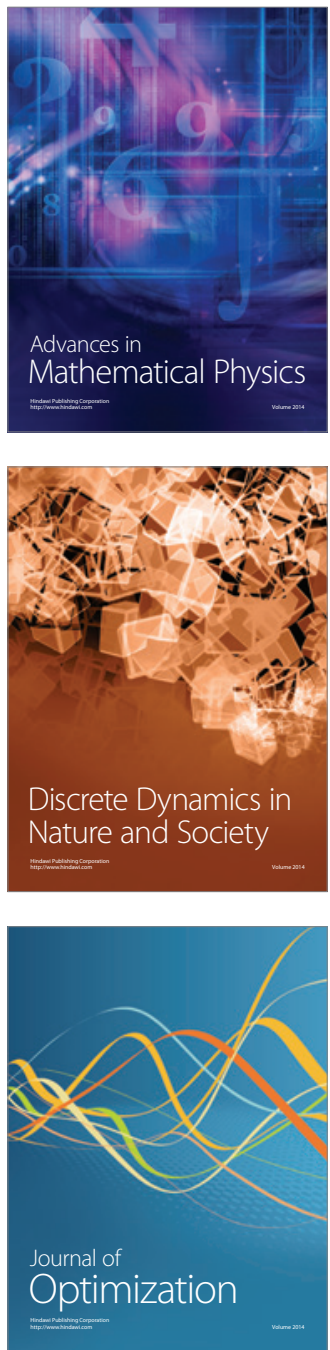